\title{
Article
}

\section{Totalistic Programs for Youth}

\author{
A Thematic Analysis of Retrospective Accounts
}

\author{
Mark Chatfield \\ University of Florida
}

\begin{abstract}
Recent annual estimates suggest that in the United States, approximately 57,000 young people are placed by their parents into some type of residential treatment program. Parent-pay programs are exempt from federal safety standards and some states provide little or no regulatory oversight. Federal investigations revealed a nationwide pattern of institutional abuse across multiple facilities, and some professionals have noted 'cruel and dangerous uses of thought reform techniques' within such programs (U.S. House of Representatives 2007, 76). This article summarizes qualitative research based on interviews with 30 adults who lived for an average of 20 months within a 'highly totalistic' youth program. The concept of totalistic treatment was operationalized and measured with seven key identifiers found in the literature. Twenty-five different programs of four general types were represented: therapeutic boarding schools, residential treatment centers, wilderness/ outdoor programs, and intensive outpatient programs. To organize qualitative findings, three themes explaining the experiences, immediate effects, and long-term impacts of treatment help to reveal implicit meanings woven throughout the interviews. By understanding a wider range of experiences associated with totalistic programs, efforts to improve quality of care and strategies to prevent harm may be improved. Harm prevention efforts would benefit from the analytical perspectives found in theories of coercive persuasion and thought reform.
\end{abstract}

\section{Keywords}

qualitative, evidence-based practices, totalism, residential treatment, youth programming, coercive persuasion, therapeutic boarding schools, thought reform

\section{Introduction}

According to the U.S. Census Bureau's most recent annual estimates for 2018, approximately 137,000 children and adolescents under the age of 18 were placed within some type of group home, residential treatment center, boot camp, or correctional facility in the United States (U.S. Census 2018). By subtracting the num- 
ber of young people who were court-ordered or placed in treatment by foster care authorities we can deduce that approximately 57,000 were placed by their parents into one of these 24-hour-a-day settings (Sickmund et al. 2017; U.S. DHHS 2018a). The legal authority behind youth placements is a key distinction because in the United States, federal safety standards do not apply to parent-pay programs and some states provide no protective oversight or regulation of these teen treatment programs (Federal Trade Commission 2019; U.S. GAO 2008b).

Young people living within these facilities are protected by a variable 'patchwork' of state policies and regional agencies (U.S. House of Representatives 2008, 51). The most recent estimates report that in 2016, there were 1,500 cases of institutional abuse documented and confirmed in the United States, but this number reflects only the official cases, and further, 11 states did not provide data (U.S. DHHS 2018b). Federal investigations by the United States Government Accountability Office (GAO) documented numerous confirmed and reported cases of abuse and deaths within private-pay treatment settings (U.S. GAO 2008a; U.S. GAO 2008b; U.S. GAO 2008c). Some professionals have noted 'cruel and dangerous uses of thought reform techniques' within these programs (U.S. House of Representatives 2007, 76).

The concept of thought reform was developed by the psychiatrist, Robert Jay Lifton, in the classic text, Thought Reform and the Psychology of Totalism: A Study of 'Brainwashing' in China (1989), first published in 1961. In that study, he identified eight key features associated with thought reform methods that were used in totalitarian prisons to change the identity, beliefs, and attitudes of prisoners, bringing them into harmony with the prosocial ideals that were valued by authorities during the Maoist revolution. Lifton was among the first to mention a comparison of totalistic treatment methods in the United States and methods of ideological totalism in China. In academic literature, this comparison was addressed also by scholars such as Edgar Schein, in Coercive Persuasion (1961), Jerome Frank, in Persuasion and Healing (1974), and Barbara Frankel, in Transforming Identities (1989). They concluded that for adults, the difference between treatment and thought reform lies not in any essential set of methods, but in the individual's freedom to exit the milieu. This perspective raises ethical questions and concerns about totalistic milieus where young people are unable to refuse treatment.

Early experimenters who developed intensive group reform methods for youth in the 1960s, such as LaMar Empey and Jerome Rabow (1962), openly compared their approach to treatment to methods of 'brainwashing' in totalitarian thought reform programs. In response to fears about the immorality of this new 'Communist' method of reeducation, they and Edgar Schein (1961 and 1962) argued that such methods were morally neutral and could be applied toward benevolent or malevolent purposes. Concerns that such methods were antithetical to American values of self-determination were countered by Schein, who explained that these were American treatment methods: 'It could just as well be argued that the Communists are using some of our own best methods of influence' (1961, 269). 
In order to call attention to the potential for harm in youth programs, drug policy experts such as Barry L. Beyerstein (1992) and Bruce K. Alexander (1990) applied classic models of thought reform to the study of teen treatment settings. Beyerstein's book chapter is a rare example of scholarship devoted to this topic. Despite the similarities between thought reform and youth treatment programs, and despite the potential for psychological harm in coercive reform methods, few empirical studies on youth treatment measure or explore key variables identified in classic theories of coercion. The American sociologist, Benjamin Zablocki (1997) argued that scholarly discussions about thought reform were lacking in objectivity and were constrained by emotional polemics. He explained how social scientists had effectively blacklisted the concept, preventing meaningful discourse.

Theories of coercive persuasion and thought reform may provide important variables to consider when studying totalistic treatment settings. These conceptual lenses could help to explain dynamics of personal change. This is an area of academic neglect, noted by many scholars who point to the need for theory explaining why and how intensive program methods act upon individuals (De Leon 2000; Edelen et al. 2007; Harder and Knorth 2015; Harper 2010; Neville, Miller, and Fritzon 2007; Whitaker, del Valle, and Holmes 2015). While the current state of the literature suffers from a lack of strong theory, residential treatment providers face increasing pressures to demonstrate the effectiveness of their methods as increasing numbers of critics argue that some group care settings are inherently inappropriate to healthy youth development (Dozier et al. 2014; Reamer and Siegel 2008; Walker, Bumbarger, and Phillippi 2015). This combination of underdeveloped theory and intensifying pressure to demonstrate results may partially explain why so many studies have focused on a narrow set of outcome variables while privileging the analytical perspectives of those who deliver treatment.

The dominant trend in research literature examines residential teen treatment from the perspective of the adults who provide care (Polvere 2011). Only a handful of studies examine first-hand accounts of the lived experiences of youths in residential settings. Mary Elizabeth Rauktis (2016) explores how young people perceive behavior management status-level systems within various types of residential settings. Samson Chama and Octavio Ramirez (2014) present a retrospective study describing program atmosphere, interactions with staff, and punishment practices, noting a general lack of research exploring the subjective experience of residential programming. Alexandra Cox (2017) presents one of the most elaborate institutional ethnographies using a phenomenological approach to feature lived experiences within juvenile justice programs. These works shed light onto the way young people construct meaning, adapt to highly controlled environments, and struggle to access psychosocial resources. Ethnographic research among adult recipients provides additional perspectives on the variety of lived experiences within high-intensity treatment settings (Garcia 2015; Gowan and Whetstone, 2012; Kaye 2012; Stevens 2012). 
The present study summarizes a qualitative research project titled, Adult Perspectives on Totalistic Teen Treatment (Chatfield 2018). This research explores the experiences, immediate effects, and long-term impacts of treatment by analyzing interviews with 30 adults who lived for an average of 20 months within a variety of 'highly totalistic' youth programs. In their retrospective accounts, they provided first-hand descriptions of life within twenty-five different programs in the United States and one American owned program in Mexico. Five were court-ordered into a program, and twenty-five were placed in treatment by their parents due to a combination of family problems, personal behavior, academic performance, and substance abuse. Four general types of programs are represented: therapeutic boarding schools, residential treatment centers, wilderness/outdoor programs, and intensive outpatient programs.

The concept of 'totalistic' teen treatment was operationalized and measured quantitatively using sampling frame data that was collected in an online questionnaire. An index variable created for the study identified seven items reflecting key totalistic program characteristics (TPC): 1) strict controls of communication; 2) peer surveillance and policing; 3) a philosophy based on the need to change the whole person; 4) a series of prescribed stages or phases of progress and privileges; 5) frequent participation in formal or informal group sessions involving confrontation, confession rituals, or prolonged interpersonal encounter methods; 6) a strict system of rules and inflexible punishments; and 7) a central authority structure that governs all aspects of life.

The sections that follow provide key theoretical foundations informing the research design and analytical perspectives. A detailed methods section reviews the sampling and screening processes that ensured breadth in the range of experiences represented. To organize findings, three main themes help to explain some of the implicit meanings woven throughout the interviews. These findings are applied to a discussion of harm in teen program settings and the prevention of institutional child abuse.

\section{Theoretical Perspectives}

Important theoretical perspectives shaped key aspects of the study. George De Leon's (2000) descriptions of autocratic therapeutic communities helped to identify some of the essential features of totalistic programs (De Leon and Melnick 1993). Frank K. Salter's (1998) perspective on the limited variability of institutionalized persuasion shaped the decision to include multiple types of programs by identifying the features they had in common. The research questions, interview questions, and interpretation of findings were informed by Kurt Lewin's (1947) three phases of personal change. These phases were described in his theory of group dynamics and then expanded by Edgar Schein's (1961) adaptation to the study of coercive persuasion. George De Leon's theoretical descriptions of the autocratic therapeutic community model provide a list of features that characterize multiple types of totalistic youth programs (De Leon and Melnick 1993). De Leon 
(2000) mentions Erving Goffman's (1961) concept of the total institution but the term, 'totalistic treatment,' goes beyond Goffman's typology of total institutions to include some of the more intrusive features described by George De Leon and Frank Salter. It was the potential for harm in this set of features that was so alarming to Beyerstein, Alexander, and to critics of Empey and Rabow.

According to Australian ethologist and political scientist, Frank K. Salter, despite differences in cultural content, institutionalized persuasion is applied with a limited number of methods that are found globally in settings of acute indoctrination. His work emphasizes the 'limited variability' of this narrow set of methods (422). Across multiple cultures, prosocial and destructive methods of indoctrination rely on a similar set of features. This perspective informed the decision to consider multiple types of youth programs within the same study by identifying a set of key program characteristics. Adding an important dimension to the discourse on treatment and coercive persuasion, Salter described six essential differences between traditional initiation rituals and methods associated with thought reform in modern organizations. Specifically, numerous features were shared, such as control of milieu, isolation from information, severance of interpersonal bonds, intense peer pressure, threats, and prestige testimonials. However, traditional milieus did not include modern methods such as routine obedience, interrogation, accusation, mild degradation with self-revelation, intense degradation with confession/apology, and punishment/reward systems (Salter 1998, 444). These traditional and modern methods are applied with varying degrees of intensity within totalistic treatment programs and totalitarian thought reform programs (De Leon 1995 and 2000; Dye et al. 2009; Lifton 1989; Ofshe and Singer 1986; Singer and Ofshe 1990).

One of the foundational models linking totalistic treatment to coercive persuasion is Kurt Lewin's theory of group dynamics (1947), which explains how and why group processes can influence individual change. Lewin's three phases of change model (Unfreeze, Change, and Freeze) was developed during WWII when worker productivity, enhanced teamwork, and popular morale were important for national defense, making them a high priority for research. Lewin believed that the capacity to predict and change social behavior might 'prove to be as revolutionary as the atom bomb' (Lewin 1947, 5). George De Leon (2000) alluded to the usefulness of Lewin's theory to explain personal change processes but it was Edgar Schein who adapted and expanded Lewin's work to explain coercive persuasion in thought reform environments. As military innovations in guided group interaction and the 'total psychotherapeutic push method' were adapted for use among American civilians, Schein argued that his theory of coercive persuasion could improve treatment methods for adult prisoners and juvenile delinquents in the United States (Knapp and Weitzen 1945; Schein 1961 and 1962).

The theoretical perspectives informing the present study are some of the foundational works that shaped the development of group dynamic approaches to treatment during the twentieth century. The program features associated with these 
approaches were relatively new in the 1960s, but they are widespread today and found in multiple types of intensive youth treatment programs. Because group dynamic approaches to treatment can be labeled with a variety of names and applied with varying degrees of intensity, foundational theories are crucial for identifying and analyzing the design features that multiple types of programs share in common.

\section{Sampling Methods}

This IRB-approved research was completed in 2018 at the University of Florida in the Department of Family, Youth and Community Sciences. In the first stage of the research, participant responses to an online questionnaire $(\mathrm{N}=235)$ were collected for quantitative analysis to create a sampling frame of potential interview participants. Two index variables were developed for the questionnaire. A quality of experience (QOE) index variable was created for this study by calculating each participant's mean score on 15 key indicator items found in the literature. Participants were asked to rate six items measuring how helpful, safe, fair, and reasonable the program felt to them. They were also asked how equally the staff treated residents and how easy it was to adjust to life after the program. They were asked to rate nine items measuring how strongly they agreed or disagreed with statements such as how much they trusted the staff, how well their basic needs were met, and the positive long-term impact of the program. Each participant was ranked according to their mean per item score on a five-point scale, producing a combined index variable representing their overall perceived QOE. To measure participants' perceptions about the design of their respective programs, an index variable asked them to rate 'how totalistic' their program was. These seven items reflected the totalistic program characteristics (TPG) listed in the introduction.

Invitations to participate in research described the nature of the study and provided a link to the online questionnaire. It was shared with numerous professional organizations, individual experts, clinicians, academicians, and authors. A total of 223 adult participants, who were 11 to 17 years old at intake, passed the first screen. The second stage of the study began with the creation of a sampling frame of potential interview participants who rated their program as 'highly totalistic.' Measured on a five - point scale, those with a mean TPC index score below 4.00 were screened out to ensure that qualitative data was collected only from those who had experienced a highly totalistic teen treatment program, defined as a TPC score of 4.00 to 5.00. A total of 212 participants rated their program as highly totalistic and these were included in the sampling frame.

Two subgroups were created based on participants' ranked index scores for overall quality of experience (QOE). The lower scoring group included 15 participants randomly sampled from those who scored QOE below $2.00(n=154)$. But for higher QOE scoring participants $(n=36)$, because so few were represented in the study, a random subgroup sampling approach was not possible. Therefore, the higher scoring group consisted of the 15 highest ranking participants who were 
willing to be interviewed; their QOE scores ranged from 4.60 to 2.60 on a five point scale. To help ensure that the two subgroups were distinct, those scoring QOE between 2.00 and 2.60 were identified as a middle scoring group $(n=22)$ and were screened out of the interview sampling frame. The screening and sampling processes are shown in Figure 1 and a descriptive summary of 'Group H' and 'Group L' are provided in Tables 1 and 2.

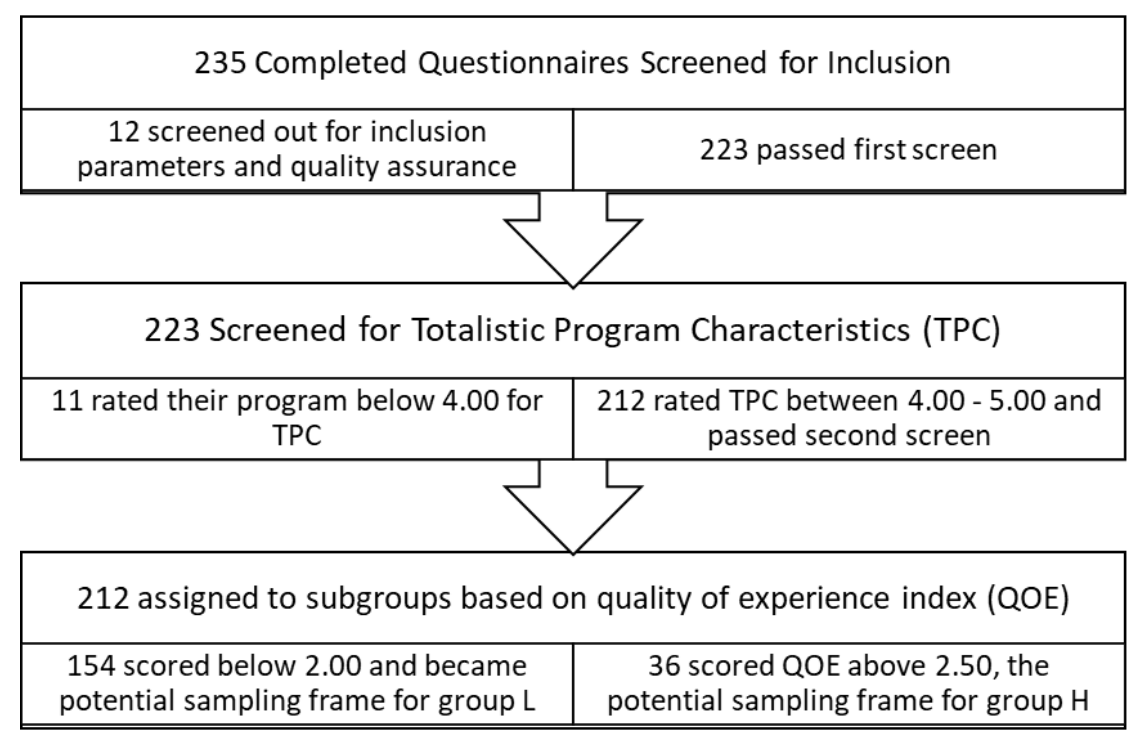

Table 1. Higher Scoring Group of Interview Participants Descriptive Data (Group H)

\begin{tabular}{|c|c|c|c|c|c|c|c|c|c|c|}
\hline Alias & Gender & Age & $\begin{array}{l}\text { Intake } \\
\text { Year }\end{array}$ & Program Type & State & Grad. & $T P C$ & $Q O E$ & $\begin{array}{l}\text { Intake } \\
\text { Age }\end{array}$ & $\begin{array}{l}\text { Months } \\
\text { In }\end{array}$ \\
\hline Lawrence & $\mathrm{M}$ & 31 & 2002 & Wilderness: ID & ID & $\mathrm{Y}$ & 4.86 & 4.60 & 16 & 3 \\
\hline Ann & $\mathrm{F}$ & 38 & 1995 & RTC/Outdoor & TN & $\mathrm{Y}$ & 4.86 & 4.00 & 16 & 12 \\
\hline Greg & M & 48 & 1985 & RTC/TBS & $\mathrm{ME}$ & $\mathrm{N}$ & 4.86 & 3.93 & 16 & 18 \\
\hline Cee Cee & $\mathrm{F}$ & 44 & 1985 & TBS & TN & $\mathrm{N}$ & 5.00 & 3.93 & 12 & 72 \\
\hline Frank & M & 23 & 2009 & TBS & MT & Y & 4.71 & 3.67 & 15 & 24 \\
\hline Howard & M & 51 & 1982 & Intensive Outpatient & $\mathrm{OH}$ & $\mathrm{Y}$ & 5.00 & 3.60 & 17 & 18 \\
\hline Yvonne & NG & 19 & 2012 & RTC & UT & $\mathrm{Y}$ & 4.71 & 3.60 & 14 & 7 \\
\hline Barry & $\mathrm{M}$ & 29 & 2004 & TBS & MT & $\mathrm{Y}$ & 4.86 & 3.20 & 15 & 22 \\
\hline Xander & M & 48 & 1985 & Intensive Outpatient & FL & $\mathrm{Y}$ & 4.00 & 3.20 & 16 & 12 \\
\hline Uriah & M & 36 & 1995 & Outdoor/JJ & FL & $\mathrm{Y}$ & 4.29 & 3.13 & 14 & 14 \\
\hline Valorie & $\mathrm{O}$ & 28 & 2004 & TBS & MT & $\mathrm{N}$ & 4.43 & 2.80 & 14 & 26 \\
\hline Nathan & M & 29 & 2003 & RTC/TBS & UT & $\mathrm{N}$ & 5.00 & 2.73 & 16 & 14 \\
\hline Iris & $\mathrm{F}$ & 42 & 1991 & TBS & ID & $\mathrm{Y}$ & 4.86 & 2.67 & 16 & 28 \\
\hline Wilma & $\mathrm{F}$ & 20 & 2011 & TBS & IA & Y & 4.71 & 2.67 & 14 & 30 \\
\hline Aaron & M & 53 & 1982 & TBS & $\mathrm{ME}$ & $\mathrm{Y}$ & 4.86 & 2.60 & 17 & 16 \\
\hline
\end{tabular}

Note. $\mathrm{NG}=$ Nongendered; $\mathrm{O}=$ Some Other Gender Identity; RTC $=$ Residential Treatment Center; TBS $=$ Therapeutic Boarding School; JJ = Juvenile Justice. Grad.=Graduated or Completed Program; Months in = \# of months in the program. 
Mark Chatfield - Totalistic Programs for Youth

\begin{tabular}{l|llllllllll}
\multicolumn{1}{l}{ Table 2. Lower Scoring Group of Interview Participants Descriptive Data (Group L) } \\
\hline Alias & Gender & Age & $\begin{array}{l}\text { Intake } \\
\text { Year }\end{array}$ & Program Type & State & Grad. & TPC & QOE & $\begin{array}{l}\text { Intake } \\
\text { Age }\end{array}$ & $\begin{array}{l}\text { Months } \\
\text { In }\end{array}$ \\
\hline Carmen & F & 41 & 1989 & Intensive Outpatient & TX & N & 4.71 & 1.80 & 15 & 36 \\
Tony & M & 42 & 1991 & RTC/TBS/Outdoor & OR & Y & 5.00 & 1.73 & 16 & 24 \\
Mary & F & 21 & 2010 & Wilderness/Outdoor & OR & Y & 4.14 & 1.73 & 14 & 3 \\
Dee Dee & F & 27 & 2004 & RTC/TBS & UT & Y & 5.00 & 1.60 & 13 & 37 \\
Elsa & F & 31 & 2004 & TBS & MX & N & 5.00 & 1.60 & 17 & 12 \\
Bobbi & F & 39 & 1994 & RTC/TBS/Outdoor & AL & N & 5.00 & 1.53 & 16 & 22 \\
Pat & F & 30 & 2001 & RTC/TBS & UT & Y & 5.00 & 1.53 & 14 & 27 \\
Kam & F & 31 & 2003 & TBS & MT & Y & 5.00 & 1.40 & 17 & 20 \\
Joan & F & 19 & 2016 & TBS & MT & Y & 5.00 & 1.40 & 17 & 18 \\
Sebrina & F & 27 & 2006 & RTC & UT & Y & 4.86 & 1.33 & 16 & 10 \\
Quill & F & 22 & 2009 & TBS & MT & Y & 4.86 & 1.27 & 14 & 24 \\
Ozzie & F & 24 & 2010 & RTC & PA & Y & 4.14 & 1.27 & 15 & 11 \\
Ziggy & F & 39 & 1994 & Intensive Outpatient & FL & N & 5.00 & 1.20 & 15 & 16 \\
Donnie & O & 19 & 2012 & RTC/TBS & IA & Y & 5.00 & 1.00 & 13 & 21 \\
Rudi & F & 44 & 1989 & Wilderness & UT & Y & 4.71 & 1.00 & 15 & 3
\end{tabular}

Note. $\mathrm{O}=$ Some Other Gender Identity; RTC $=$ Residential Treatment Center; TBS = Therapeutic Boarding School; $\mathrm{MX}=$ Mexico; Grad. $=$ Graduated or Completed Program; Months in $=\#$ of months in the program.

\section{The Qualitative Approach}

The design of this study was shaped by the pragmatic qualitative research principles described by Jamie Harding (2013) and Robert Yin (2016). Semi-structured interviews were conducted nationally by phone with 30 participants and each was recorded. Each interview was loosely structured around the same twelve openended questions, but participants were encouraged also to speak to what was most important to them. All interviews were fully transcribed and coded line by line for analysis. The interviews were developed to collect data that would be useful in answering three research questions. How are totalistic teen treatment methods experienced? How do participants describe the immediate effects of the program? How do participants describe the long - term impacts of the program?

\section{Thematic Findings}

This summary presents three themes that were developed to answer the research questions. The full report explains how these themes are grounded in qualitative data and distilled from topical, categorical, and comparative analyses. The participant names provided below are aliases.

\section{Induction/Abduction}

The theme of induction/abduction expresses a 'toward and away' motion of placement into the program and removal from the outside world. This theme is revealed in the way interview participants described being transported and introduced to the program. Rudi described a literal abduction: 'I was kidnapped to be taken out there, my parents hired a transporter that came into my room and like, woke me up and searched me and took me away.' Pat linked the abduction experience to a shocking intake procedure: 'I was terrified when I went because they grabbed me out of my bed in the middle of the night.' 
For Mary, after being tricked into the program, her induction/abduction was overwhelming and disorienting. 'From the very beginning of the program - when I said one of the biggest emotions for me was pure confusion, fear and confusion, well, I was tricked into going, my parents told me we were having brunch with a family member out of town.' When she was 14, after her parents caught her smoking marijuana, they took her to a strange house in the woods. There she learned that she would be spending several weeks on a hike with strangers, walking all day, every day, in silence. First, she was taken to the basement and strip searched. 'They took one of us at a time into the back room and did a strip search, which at the time I had no idea what was happening, I didn't know who these people were, where my parents were, anything.' Then she was put into a windowless van and forbidden to speak or ask questions on the drive through the night.

They didn't explain much. One of the things that they said over and over and over was 'no questions, no questions,' so obviously a lot of us were asking a lot of questions, were trying to. I wasn't necessarily, I was just kind of stunned.

The van stopped around 4:00 A.M. and she was assigned a backpack so heavy she could not lift it by herself. At the time, she weighed 105 pounds and for the next three weeks, her treatment consisted of walking in silence with a 65 - pound backpack strapped to her shoulders. During this time, she was allowed to eat only beans and rice, and allowed to drink only small amounts of collected water, which was sometimes muddy and always treated with iodine. At the time of her interview she still experienced physical pain where the backpack straps cut into her shoulders during her initiatory hike.

In all program types, as initiates struggled to get their bearings, they were threatened with harsh punishments that could be given without explanation or warning. Iris was punished for breaking rules and 'agreements' she knew nothing about.

They tell you there's only three rules here, 'no sex, no violence, and no drugs,' so those are the only rules, everything else is called an 'agreement' and they don't tell you that you're out of agreement until you break the agreement, so the first few months are just kind of like, you know, you feel like a puppy waiting to get your nose smacked.

Protesting unfair punishments or questioning the program's logic could invite even more restrictions. As the structure's power was induced, the outside world, old habits, and the old self, became farther away. A few participants described the in duction/abduction experience in positive terms. To Lawrence, being led away from the past and his old friends was a good thing. 'The whole point of the program is to take you away from your support system and all the things that completely take your mind off of what's important in real life.' In sharp contrast with Mary's experience, Lawrence's induction was facilitated by helpful staff members. 


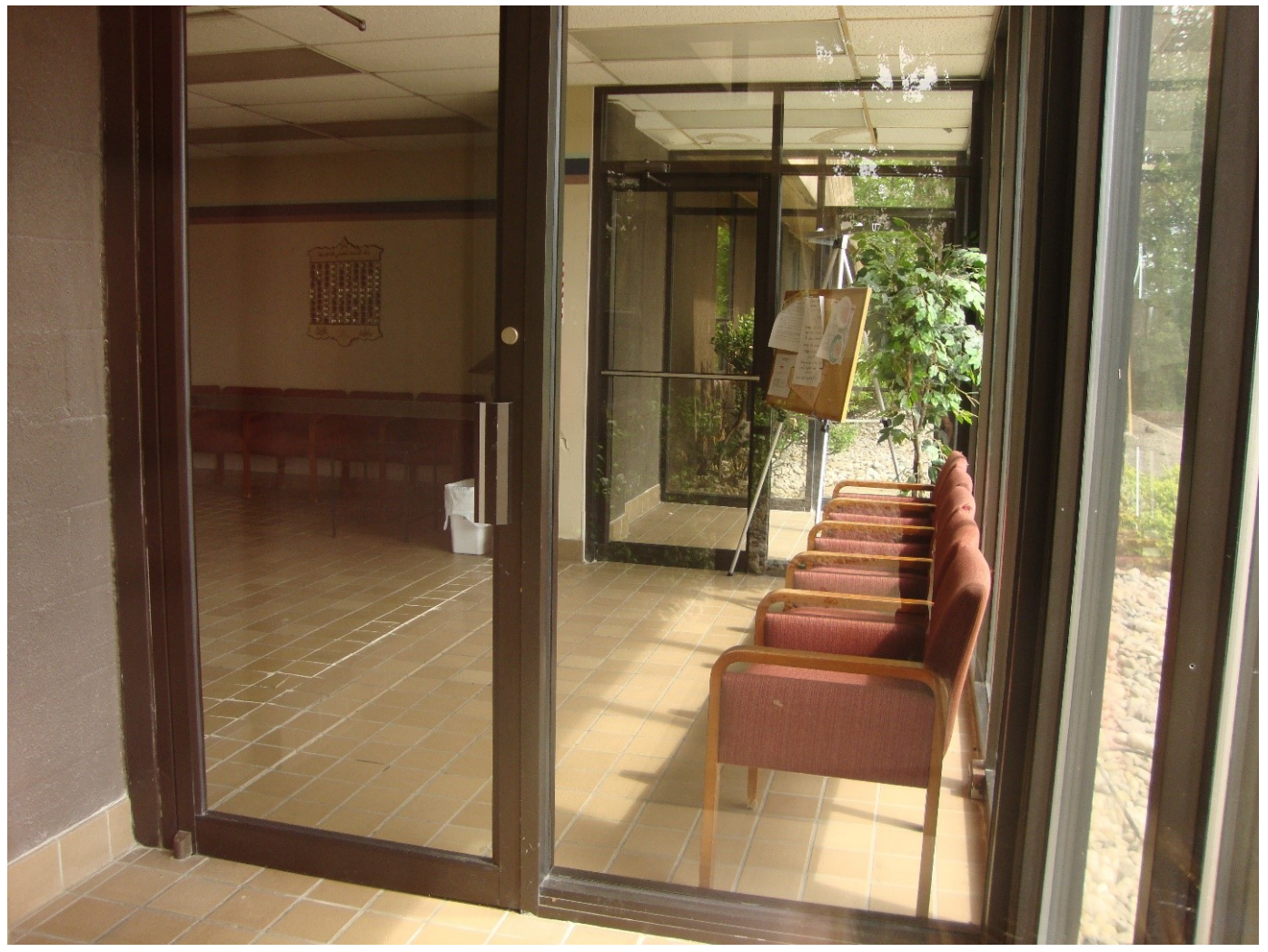

Photo 1. by Mandy Carlisle, 2012, Milford, Ohio. Front entrance. ${ }^{1}$

There was no rulebook, there were staff members who were explaining it as best as they could and walking you through and getting you changed, getting you out of your civilian clothes, and getting you prepared with all your physical stuff you're going to need for the program you know. There was a lot of explanation going on there and they were always willing to answer questions and stuff like that at appropriate times.

The singular motion of this theme, being led away from the past and led toward a future self, describes the simultaneous 'tearing down of the old selves and the building of new ones' (Adams 1995, 101). Participants referred to the induction/ abduction process as an experience that taught them there was one choice: resist and suffer indefinitely or comply and rise up through the levels of the program toward release.

\footnotetext{
1 Photos 1-5 were taken between 1982 and 2008, the facility shown housed three different teen treatment programs: Straight, Incorporated, Kids Helping Kids, and Kids Helping Kids, A Pathway Family Center. More information about the site is available here: http://survivingstraightinc.com/kids_helping_kids_-_straight_renamed
} 


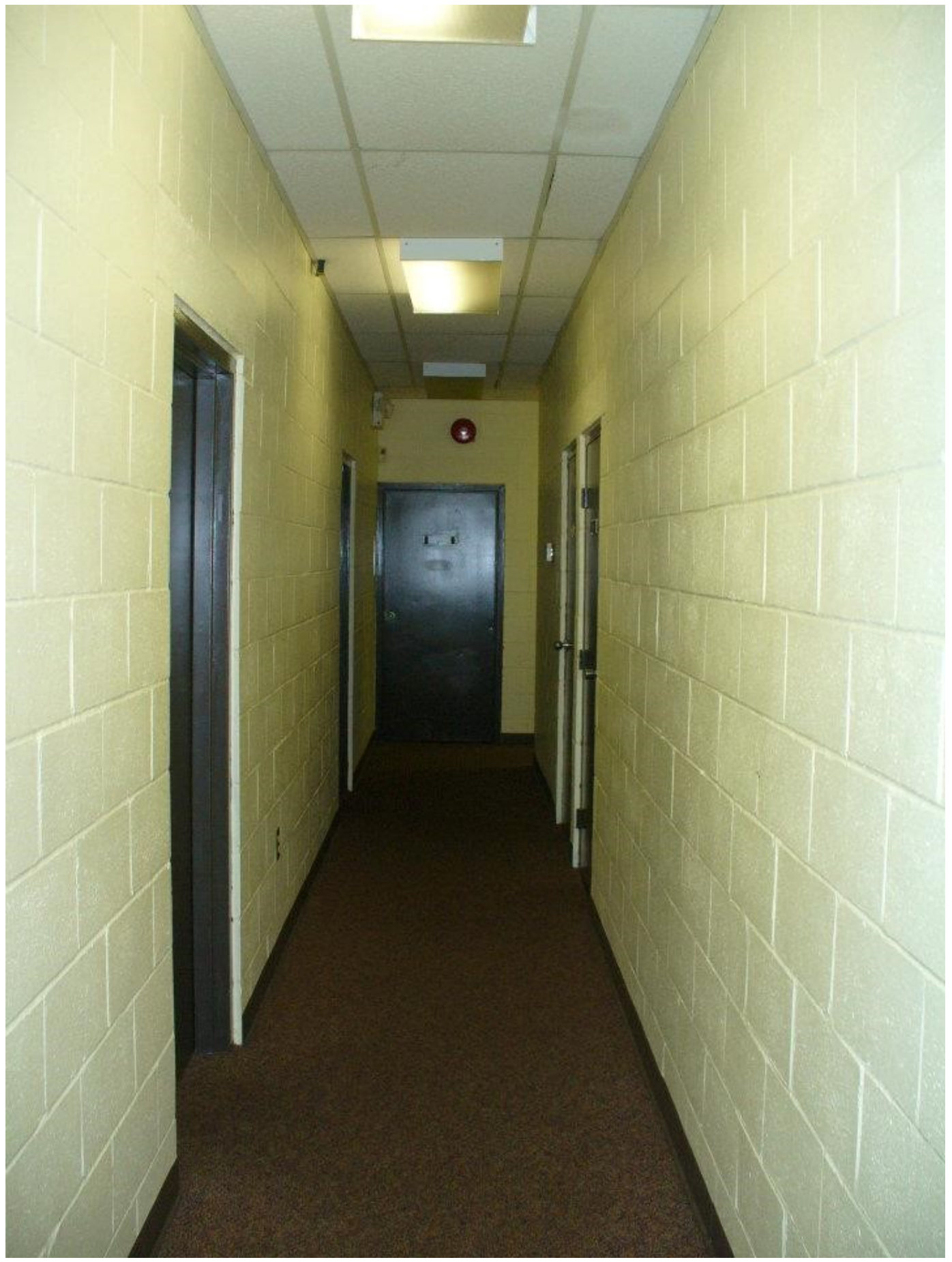

Photo 2 by Mandy Carlisle, 2012, Milford, Ohio. Hallway to intake rooms.

\section{Containment/Release}

The theme of containment/release reflects the short-term desire for internal relief and the long-term goal of actual release from the containment structure of the program. Interactions within the program environment create a milieu of transformation where youth actively participate in their own containment and the contain- 
ment of others. This theme reveals a circular logic based on participant descriptions of four interlocking conditions: 1) the only way out is to work up through the program levels, 2) resistance, lack of compliance, or complaints are seen as a symptom of a personal disorder, never indicative of some larger systemic problem, 3) the more resistant or disordered you are, the more treatment you need, and 4) progress and graduation are only possible for those who establish a genuine emotional bond with other residents and staff that demonstrates their commitment and gratitude for the program.

Ann's description of her 'big internal change' helps to demonstrate how containment and release are intertwined. One of the most important moments in her treatment was the sudden flash of insight triggered by a staff member who pointed out that Ann's mother could choose to abandon her, refusing to let her come home after the program. Rather than feeling threatened, Ann remembers opening up, realizing she was deeply connected with all the people in her life. Rather than feeling coerced, she described this as a process of becoming more authentic, enabling her to embrace the program with more depth. She emphasized that this transformation only occurred after many months of adhering to the program's strict regimen.

I talked about all the hard stuff with my stepdad and I talked about all that, but I think that ultimately the big change hadn't happened within me. Like, I've done all the external stuff you know, but see, I had started going to therapy when I was seven years old, so at that point I knew all the words to say, I knew how to participate, I knew how to not get in trouble, I knew how to do the stuff, but the big internal change hadn't really happened as far as being myself for who I am I guess, and so, I think that that's just a long process.

She reported a long process leading up to the big change, but the moment of change was a sudden flash of insight that taught her humility.

Somehow, I learned humility and that was my big lesson, that was my biggest lesson from my whole experience there...it was a huge turning point. And I think that if it all hadn't happened exactly the way it did, if I hadn't been isolated for a month...I mean this packet they gave us to do, the fourth step [of Alcoholics Anonymous] was so in - depth...if all of those things hadn't happened exactly the way they had I don't know that I would've had such an experience.

This month - long period of isolation for her fourth step was an unexpected punishment that set the stage for her moment of internal change. She had been in the program for 10 months by then and was progressing along quite well when the staff decided she needed a demotion. 


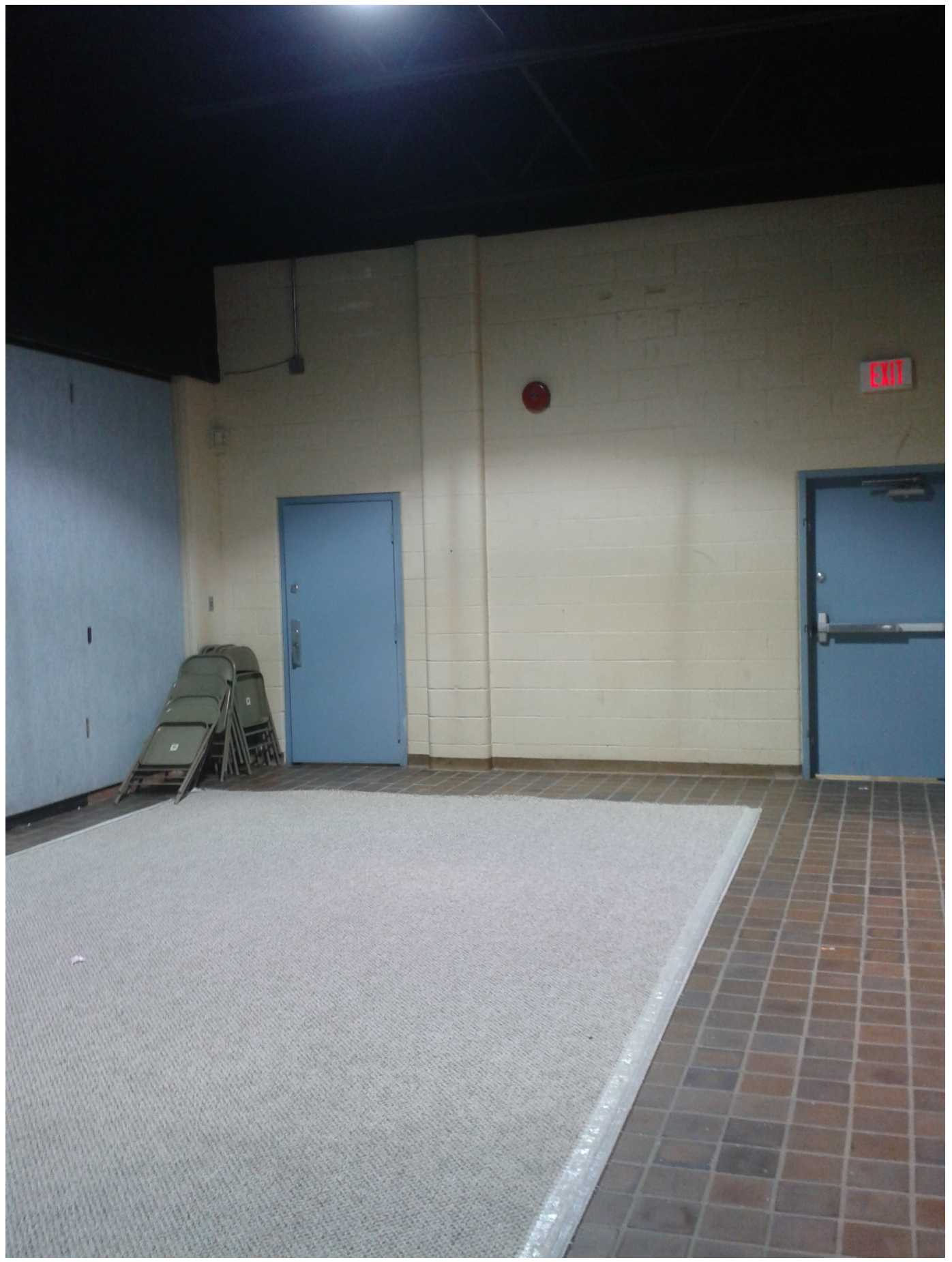

Photo 3. by Phillip Laurette, 2012. Milford, Ohio. Rap room.

I'd been there for about 10 months and I thought that I was progressing really well through the program, and then at the last minute, right as I was about to move up to the new level in the program, they turned around and took it away from me and actually put me on kind of like, this isolated thing. It was a really 
wild kind of moment because they actually decided that the way that I'd been interacting with my mother and the way that I'd been interacting with the rest of the group was really controlling, and you know, that I was just kind of like skating through and that it wouldn't really be right for me to move up. And so, here I thought that I was about to get to move up to the next level and actually they drop me down to like, below the first level.

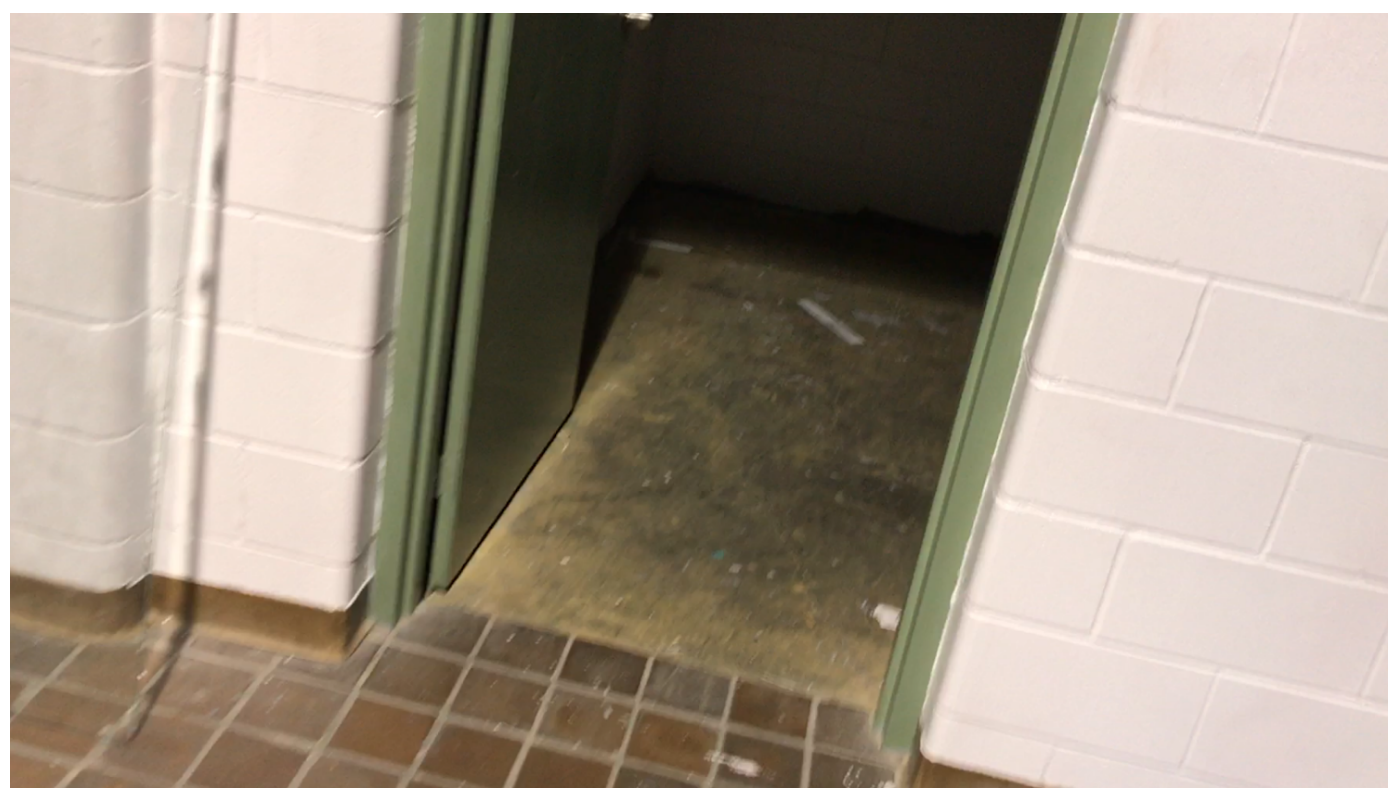

Photo 4. by Kathy Moya, 2017, Milford, Ohio. Time out room.

This setback meant she lost privileges and would have to spend each day in isolation, called 'blackout.'

When the whole group was all eating together, I was sitting over in the corner, if they were all standing around, I was off to the side facing the wall. I didn't have to participate in chores, I didn't have to participate in work. If everybody else was chopping wood, I was sitting over next to a tree facing the tree all day.

Rather than framing her punishment as an arbitrary setback or an unwarranted seclusion, she remembers learning humility. It was after this month in blackout when Ann's therapist reminded her that her mother could refuse to take her back.

So I was really kind of confronted with that possibility and then the next day I did my fifth step which is where you kind of, in recovery you don't necessarily read your fourth step to the person but you kind of talk about what you found out about your- 
self in your fourth step, and that was really illuminating for me and that was really the big turning point, that weekend.

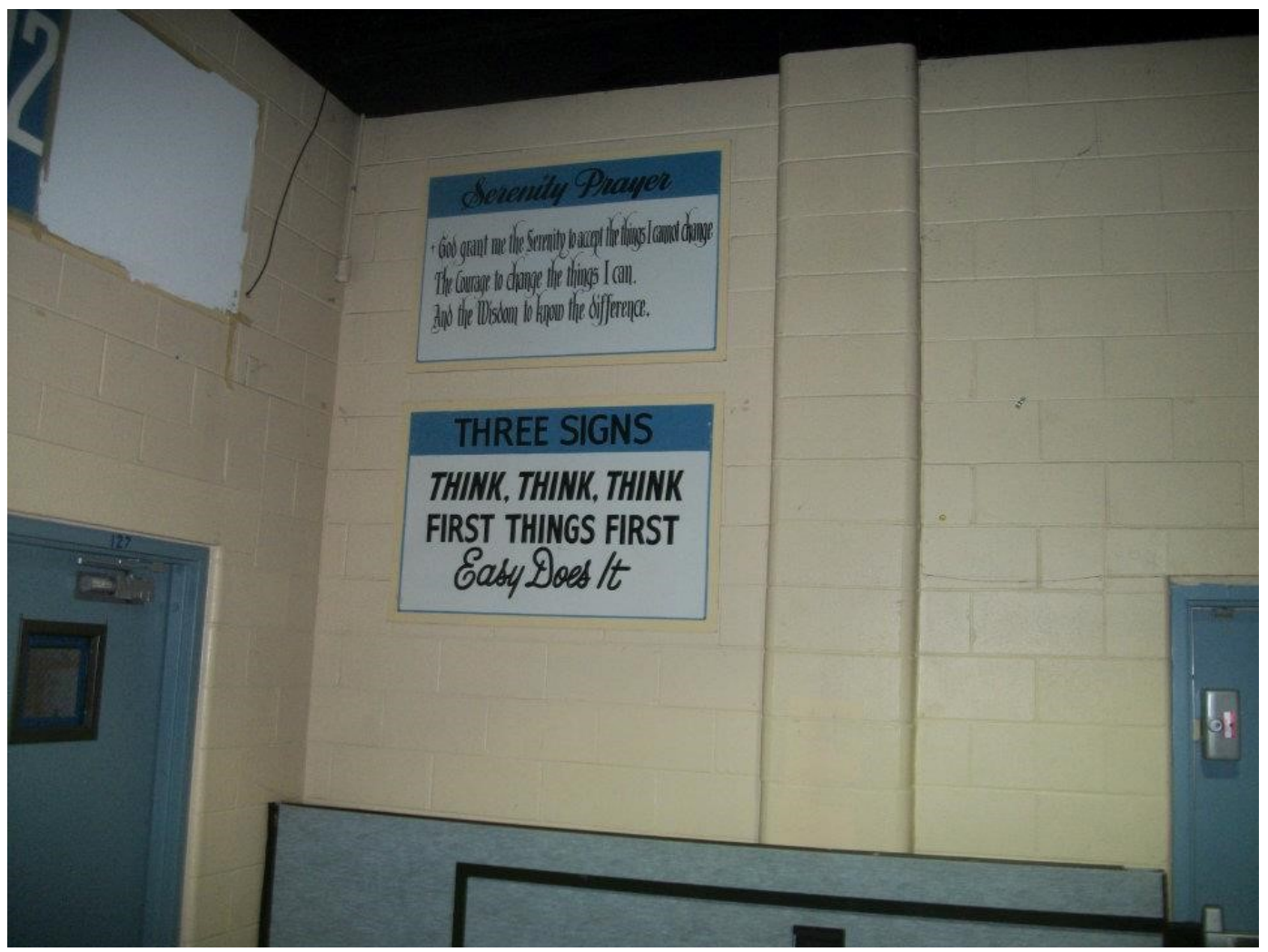

Photo 5. by Mandy Carlisle, 2012, Milford, Ohio. Slogans.

Across the interviews, participants described how the program structure provided rigid boundaries against the outside world while softening or violating interpersonal boundaries within the milieu. Even those who praised the program's effects described the constant pressures as a general sense of dread, a fear of unpredictable confrontations, an exhausting schedule, and a constant threat of punishment. For the majority, these pressures were described as stressful or traumatic, but at the time of her interview, Ann saw these as positive experiences and opportunities. "The phrase that the program director would say all the time was "everything we do is therapeutic," and so you know, there was always - they're always finding new ways to poke at you so that you could explore your issues.' Unlike Ann, who embraced the unexpected, Nathan described the threat of unpredictable punishments as constant pressure: 'It felt like all the moments that I was happy there were a reprieve from the constant, like, oppression.' He explained that his favorite time of day was when he was finally allowed to go to sleep, and his least favorite time of day was waking up in the morning.

Others made no attempt to frame the experience in positive terms. In one understated sentence, Kam revealed a potentially harmful aspect of containment/release 
that many spoke to: 'It could be hours that you are getting screamed at, and the best way to avoid a heavy confrontation was to confront other people about things that you saw them do.' By deflecting attention onto others in cathartic confrontations, frustrated emotional pressures may be released. And when such deflections demonstrated compliance with staff expectations, that temporary relief was coupled with rewards of status and progress toward actual release as graduation.

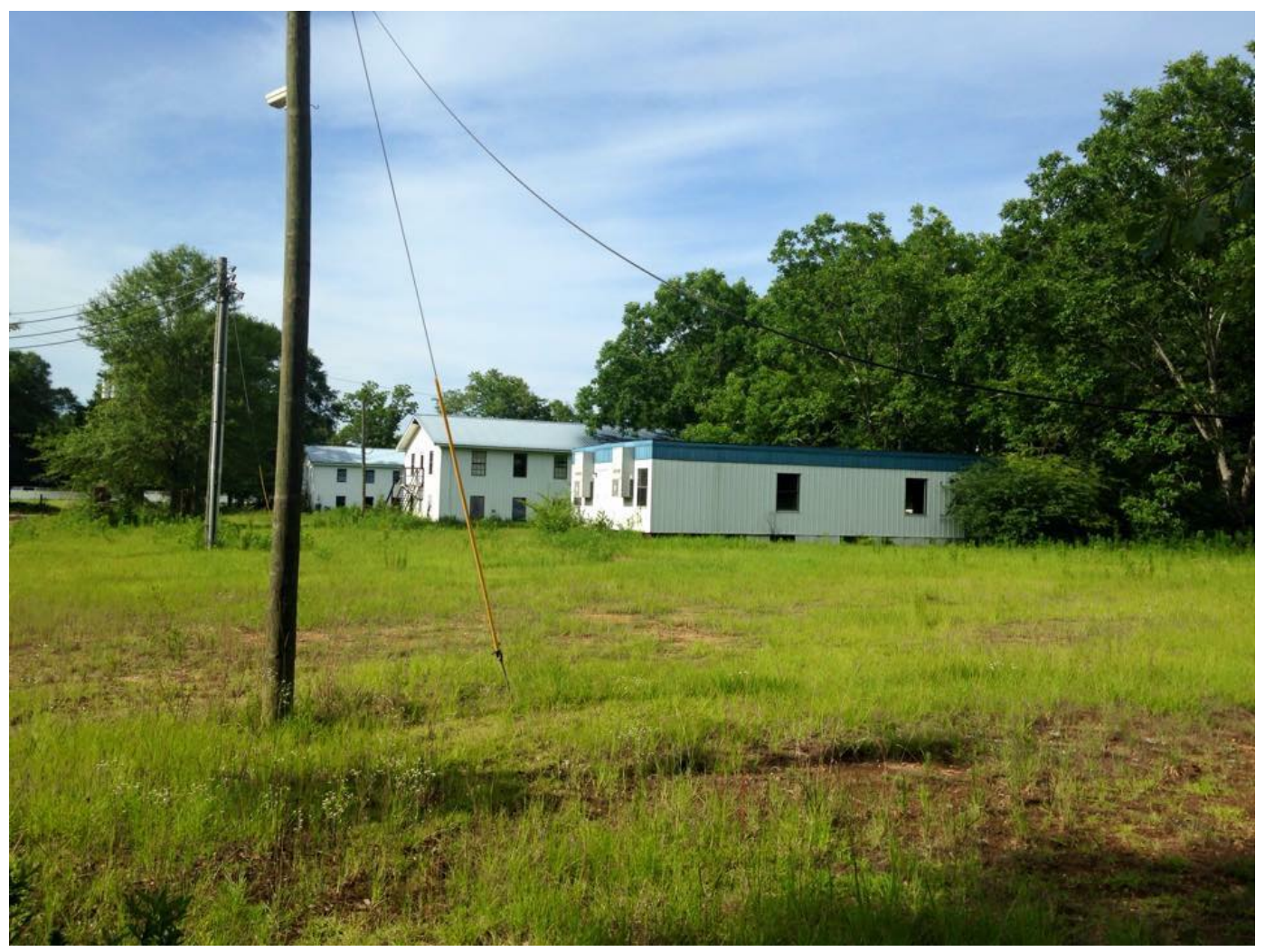

Photo 6. by Lillian Speerbrecker, 2015, Lucedale, Mississippi. Facility grounds. ${ }^{2}$

Ironically, the only way to earn release from the container was to become an integral part of the container. Rudi mentioned the most basic expression of this theme when describing the social environment: 'The program encouraged us...to punish people who didn't hike fast enough, or you know, fall in with the group.' Joan explained that there were consequences for not becoming part of the container: 'I was responsible for making sure these other people get their stuff done, otherwise I would get in trouble.'

2 The facility shown at photos 6-8 housed a succession of different programs that apparently operated from the 1970s until 2011 or 2012, when the most recent program, Gulf Coast Academy, ceased operations there. More information about this site is available here: http://www.heal-online.org/ noeagles.htm and here: http://www.secretprisonsforteens.dk/fornitswiki/index.php/Gulf_Coast Academy 
Release came through performing officially sanctioned responses. Whether the performance accompanied therapeutic changes or not, they were designed to increase the power of the program. In one even - handed statement, Frank explained the logic and power expressed in the theme of containment/release: 'While I appreciate things I gained from that experience, I think there was a level of brainwashing that happened in that space. Like, your life becomes this bubble, and your life becomes "how do I get out?" and you start kind of like, performing for the system.'

\section{Trajectory and Perspective}

The theme of trajectory and perspective helps to conceptualize the way the totalistic teen treatment experience relates to the arc of life after exiting and the way that arc is viewed. This theme is perhaps most vivid when exploring attitudes toward harm that is associated with the treatment experience. At the time of his interview, Lawrence was a $\mathrm{PhD}$ student with the goal of working as the director of a wilderness therapy program. In his view, reports of harm are to be expected, and sometimes, those who claim to be victims may bear some of the blame. His concern about the portrayal of harm was linked to his interest in being interviewed.

The thing that people don't talk about when it comes to these programs is yeah, there are a lot of kids that go out there and have a really bad time, don't listen to directions, get hurt or whatever it is, and that's just kind of the nature of the beast. So anyway, I just wanted to have an opportunity to speak my part. I think it's way more beneficial than not... I'm on a couple of different groups on the internet and you know, it's about 50/50 $50 \%$ of people say that they have PTSD and stuff like that from it, and other people say it was awesome, so it's just a mixed bag. Just like any therapeutic model, it doesn't work for everybody.

Like Lawrence, Mary was also interested in working with young people, but her experiences of harm gave her a different perspective. At the time of her interview, painful physical injuries sustained in the program were interfering with her secondary education.

I have such a great interest in working with teens in similar situations so that's really what I've done with my life, until recently, is work towards that. And I believe that going through something like that really helps you develop a great sympathy and empathy for others. And I've used that trait of mine in deciding what career I want to choose for myself. But it's also, obviously the chronic pain is something that affects every aspect of my life so that's been something huge that I would say came from this program. 
Those who experienced psychological trauma described a long process of coming to terms with harm in their engagement with healing. In Elsa's perspective, after exiting the program, her life was impaired by trauma responses for many years.

I really didn't have any coping mechanisms to kind of deal with the things that had affected me and I kind of shut down in a lot of ways ... I was just kind of in this overall numb state of life in general. It was really bad especially the first couple years after I got out. I started doing therapy about a year ago and did some trauma therapy ... I mean that's like 12 years that, I would honestly say that's probably about how long it took for me to really come out of it in a real impactful way.

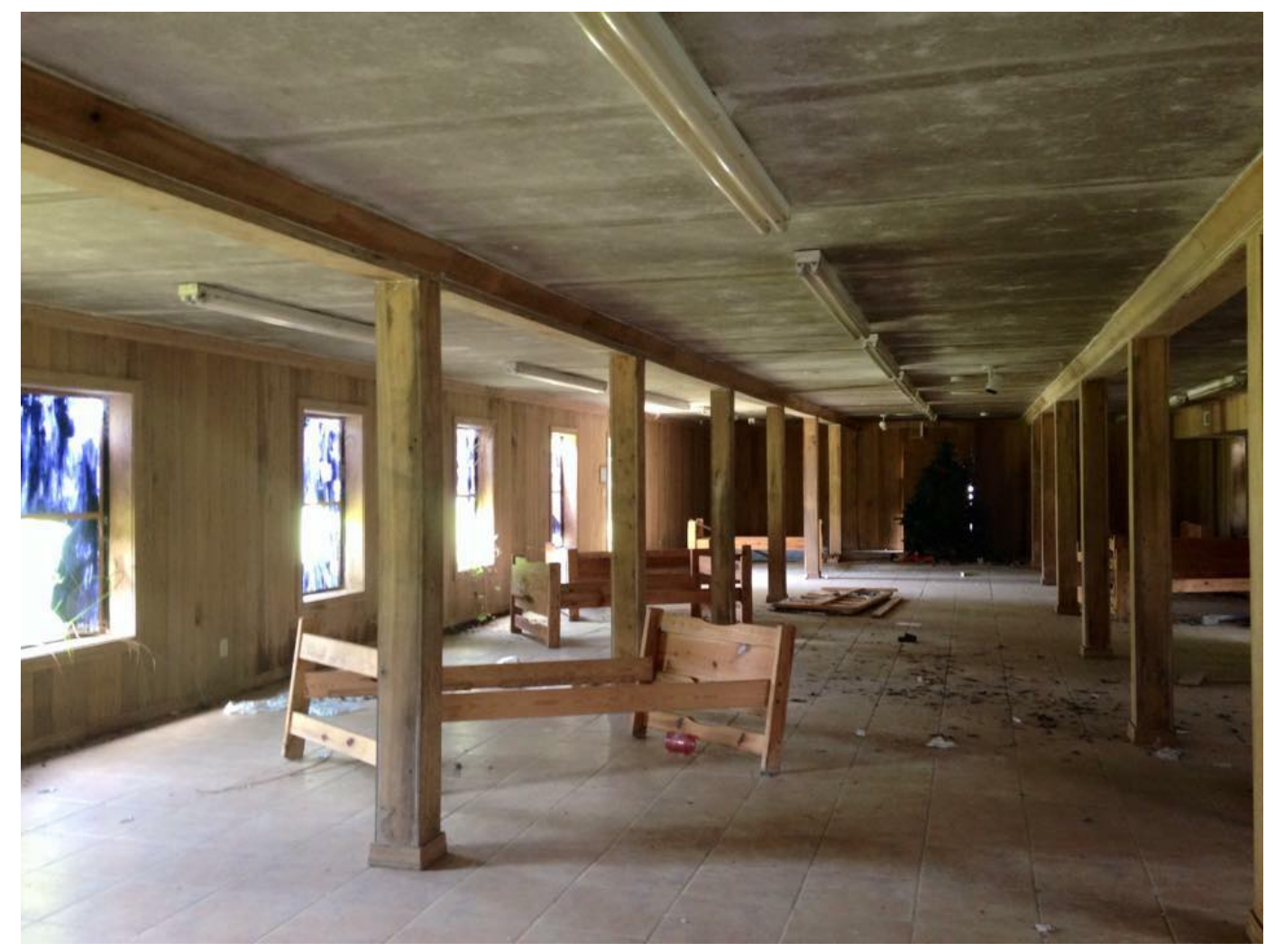

Photo 7. by Lillian Speerbrecker, 2015, Lucedale, Mississippi. Dorm room.

Nathan's perspective was informed by the experience of serious harm as well as personal growth he attributed to friendships made in the program. While he valued the help he received, he was sceptical of recent graduates and their zealous praise for treatment.

I've seen people [online] who've done different years say they had a great experience. Kind of like, "You have that post [program] glow. Give it another five months and come back to us, 
we'll see what you're gonna say once, you know, that kind of brainwashing wears off and your perspective changes and you really start thinking about everything you went through."

Whether or not they perceived help, harm, or a complicated mix of both, the degree to which they were transformed or traumatized, and the resources available to them after release, all reflect the theme of trajectory and perspective.

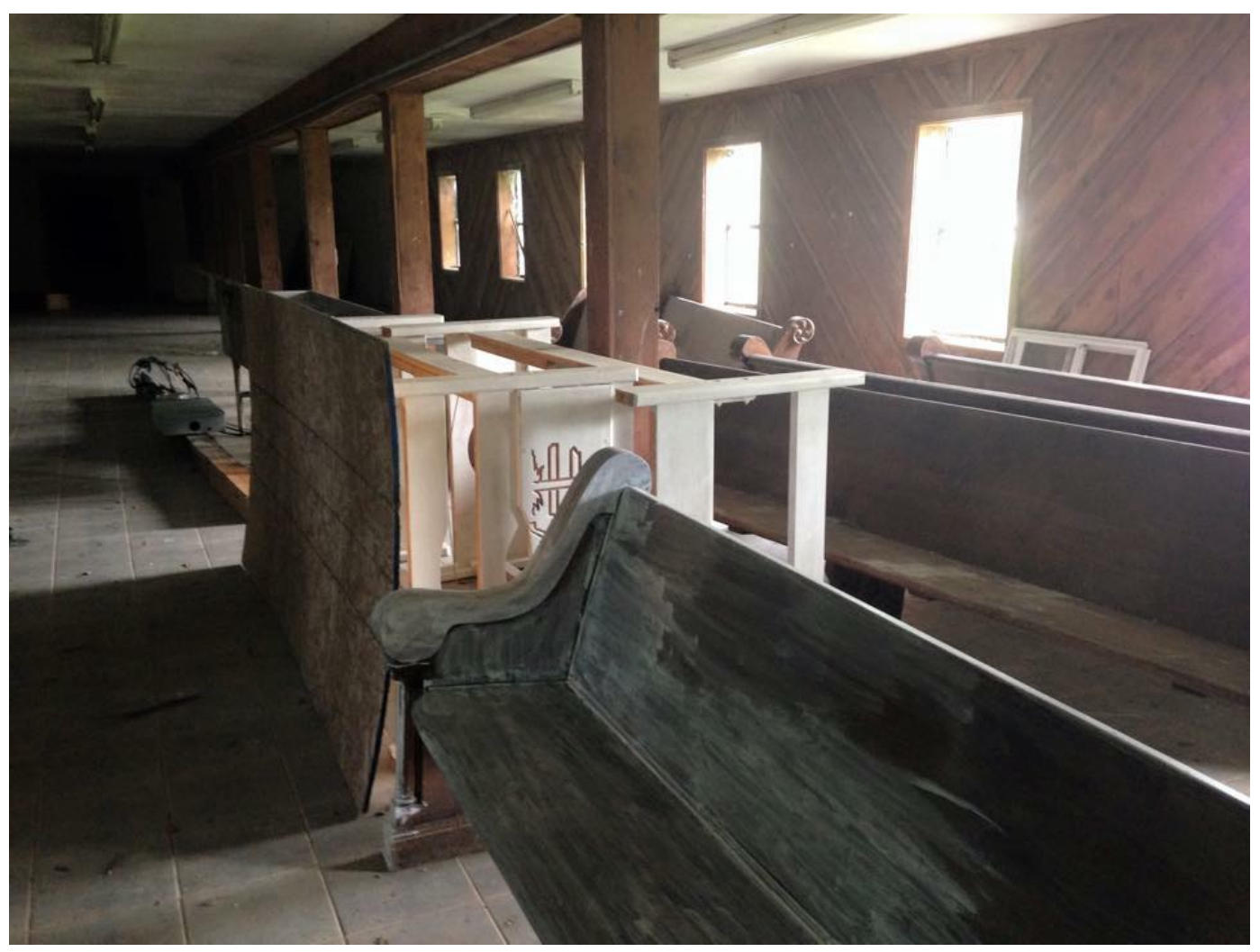

Photo 8. by Lillian Speerbrecker, 2015, Lucedale, Mississippi. Pews.

\section{Discussion}

The findings in this study highlight the importance of understanding the subjective experience of harm in teen treatment settings. Twelve participants $(80 \%)$ in the lower QOE scoring group and four (27\%) in the higher QOE scoring group named symptoms associated with traumatic stress as some of the most impactful aspects of treatment. Participants explicitly linked program features to negative outcomes such as: panic attacks, debilitating anxiety, flashbacks, triggering reminders, nightmares, mistrust of clinical professionals, difficulties in relationships, social isolation, lost sense of selfhood, and a lingering sense of violation. These participants attributed harm to unethical staff behavior, medical neglect, and interpersonal abuse, but they emphasized also that the totalistic design features of their respective programs were a primary cause of psychological injury. 
The subjective nature of program effects is perhaps more complicated when the experience of institutional abuse is framed in beneficial terms. Five participants in the higher QOE scoring group attributed beneficial responses to practices many professionals might judge as unethical, including: staff ridicule, arbitrary setbacks, public humiliation, extreme restrictions on communication, prolonged social isolation techniques, and unreasonable punishments. These participants indicated that they realized others in their cohorts experienced harm from some of the same program features they found helpful. Some simply referred to themselves as 'one of the lucky ones,' but others struggled to reconcile the discrepancy.

Many in the lower QOE scoring group indicated that their perspective on treatment changed drastically over the course of many years. Some reported a disillusionment process similar to what Nathan described; as recent graduates they believed they had been saved, but as time wore on, they realized that what they once thought of as treatment was actually institutional abuse. For some, the ethos instilled in treatment trained them to take responsibility for their role in negative life events. Failing to hold themselves accountable by criticizing the program would have signaled a backsliding. In their view, the treatment itself prevented their ability to recognize, critique, and heal from negative program effects. For others, their parents were trained to watch for complaints as a sign that they may not be ready for life outside the program, effectively linking criticism to the threat of readmission. A few reported that the program improved their family relationships but most described broken trust and impairment to parental relationships as current challenges or something the program worsened.

The thirty people who were interviewed in this study received treatment between 1982 and 2017. Some of the most extreme forms of institutional maltreatment were reported by participants with relatively recent intake dates. Compared to past decades, there may be fewer overtly brutal treatment programs in the United States now, but the prevalence of institutionalized abuse is a current topic that warrants research.

One of the strengths of this study is that it begins to portray the complex 'totality of conditions' that combine to shape personal experiences of harm (Leach 2016). If the prevention of harm in treatment settings requires the ability to identify and measure problematic design features that combine to produce unacceptable levels of risk, then treatment providers, regulatory agencies, and researchers will need to distinguish between acceptable and unacceptable risks and injuries.

\section{Limitations}

This study offers a rare glimpse into what many scholars refer to as 'the black box' of residential treatment (Harder and Knorth 2015). Although the study's focus on totalistic programming makes an important contribution to the literature by providing a wide range of research variables related to treatment quality and the prevention of harm, this focus is also a weakness because it limits the ability to ex- 
plain how critical factors such as race and class may interact to shape experiences, immediate effects, and long-term impacts. Almost all of the people who responded to the invitation to participate in research had been placed in a private-pay program by their parents and identified as white. In a larger study that could recruit participants from the general population, a focus on race and class might help to increase the relevance and generalizability of any findings.

In data collection and analysis, the topic of gender was not placed in a central position. This weakness reflects the pragmatic constraints that made an expanded scope impossible. Gendered differences were perhaps most apparent in reported reasons for placement, but by chance of the random draw, the lack of males in the lower QOE scoring group limited the ability to develop a gendered analysis. The unique nature of harm experienced by females who reported 'slut shaming' and staff interest in sexually explicit disclosures seems to indicate that power over female residents may have been leveraged more often in ways related to sexuality.

The concept of totalistic teen treatment is a new way to evaluate treatment environments and the study is limited by its exploratory nature. The two index variables demonstrated strong internal validity, with each item contributing to the discriminatory power of their respective sets. But the qualitative findings indicate that new QOE index items are needed to measure experiences of medical neglect, abandonment and betrayal, torture, or witnessing a death in the program.

Any weaknesses associated with retrospective studies should be weighed against the dynamics present within youth programs that equate ingratitude with personal failure. Interviewing youth who are currently in treatment can place them in jeopardy if their complaints are punishable or likely to be diagnosed as a failure to respond to treatment. Considering the restrictions against free communication and the risk of placing youth in jeopardy, retrospective interviews might be the most ethical and accurate way to conduct research on this topic.

\section{Conclusion}

In this summary article, three themes help to describe the experiences, immediate effects, and long-term impacts of totalistic teen treatment. Thirty interview participants provided candid windows into the way they remember and understand the meanings and values associated with their respective programs. In the sampling frame, a total of 71 different program facilities located within 25 different states were rated 'highly totalistic,' defined as a score of 4.00 to 5.00 on a five-point scale. The number of current programs that might be rated this way by former residents is unknown. If federal legislation were passed, creating uniform safety standards and a centralized data collection system in the United States, population sizes and program typologies might become clearer. Currently, due to a 'glaring lack of information,' even some of the most basic questions about residential programs go unanswered (Friedman et al. 2006, 295). 
This study found that a majority of interview participants who participated in highly totalistic programs described treatment methods that fit professional definitions of institutionalized abuse (Harrell and Orem 1980). To predict and prevent harm in teen treatment settings it is necessary to understand the problematic features associated with experiences of coercive persuasion and thought reform in youth programs. This study identifies a set of features that are found together in multiple types of youth treatment programs where the experience of harm may be common. If it were possible to measure the presence of problematic program characteristics, efforts to prevent institutionalized abuse might be improved.

\section{Acknowledgements}

This study was possible because of the many people who completed the questionnaire and the 30 people who participated in an interview. Thank you for your time and candor. David Diehl, Jodi Lane, Suzanna Smith, Sebastian Galindo, and Tracy Johns advised me with the thesis project that is summarized in this article. Their expertise and mentorship enhanced the quality and rigor of the research. This manuscript was improved greatly by Cindy Coalter and the anonymous expert reviewers who provided generous comments and suggestions

\section{Author Bio}

Mark Chatfield studies US History and works as a PhD student at the University of Florida (UF). He received an Individualized Bachelor of Arts degree at Goddard College and a Master of Science degree at UF in the Department of Family, Youth and Community Sciences. A summary of his graduate thesis was published in Child Maltreatment in Insular \& Isolated Communities (2018), an edited collection by the Child Welfare League of America and the Field Center at the University of Pennsylvania. Some of his historical essays are available online at POINTS: The Blog of the Alcohol and Drugs History Society.

\section{References}

Adams, David W. 1995. Education for Extinction: American Indians and the Boarding

School Experience, 1875 - 1928. Lawrence: University Press of Kansas.

Alexander, Bruce K. 1990. Peaceful Measures: Canada's Way Out of the 'War on Drugs.' Toronto: University of Toronto Press.

Beyerstein, Barry L. 1992. "Treatment, thought reform, and the road to hell." In Strategies for Change: New directions in Drug Policy, edited by Arnold S. Trebach and Kevin B. Zeese, 245 - 251. Washington, D.C.: Drug Policy Foundation. 
Chama, Samson, and Octavio Ramirez. 2014. Young People's Perceptions of a Group Home's Efficacy: A Retrospective Study. Residential Treatment for Children \& Youth, 31(2),120 - 134. https://doi.org/10.1080/0886571X.2014.918442

Chatfield, M. M. 2018. "Adult Perspectives on Totalistic Teen Treatment: Experiences andImpact." Master's thesis. University of Florida. Digital Collections Institutional Repository. http://ufdc.ufl.edu/UFE0052745/00001

Cox, Alexandra. 2017. Trapped in a Vice: The Consequences of Confinement for Young People. New Brunswick: Rutgers University Press. https://doi.org/10.2307/j.ctt2050wn2

De Leon, George. 1995. "Therapeutic Communities for Addictions: A Theoretical Framework." International Journal of Addictions, 30(12), 1603 - 1645. https://doi.org/10.3109/10826089509104418

De Leon, George. 2000. Therapeutic Community: Theory, Model, and Method. New York: Springer Publishing Company.

De Leon, George and Gerald Melnick. 1993. "Therapeutic Community Survey of Essential Elements Questionnaire (SEEQ), Short Form.” New York: Community Studies Institute. http://www.ndri.org/manuals-instruments/ seeqshor.doc

Dozier, Mary, Joan Kaufman, Roger Kobak, Thomas G. O'Connor, Abraham Sagi - Schwartz, Stephen Scott, Carole Shauffer, Judith Smetana, Marinus H. van IJzendoorn, and Charles H. Zeanah. 2014. "Consensus Statement on Group Care for Children and Adolescents: A Statement of Policy of the American Orthopsychiatric Association." American Journal of Orthopsychiatry, 84(3), $219-225$.

https://doi.org/10.1037/ort0000005

Dye, Meredith Huey, Lori J. Ducharme, J. Aaron Johnson, Hannah K. Knudsen, and Paul M. Roman. 2009. "Modified Therapeutic Communities and Adherence to Traditional Elements." Journal of Psychoactive Drugs, 41(3), $275-283$.

https://doi.org/10.1080/02791072.2009.10400538

Edelen, Maria O., Joan S. Tucker, Suzanne L. Wenzel, Susan M. Paddock, Patricia A. Ebener, Jim Dahl, and Wallace Mandell. 2007. "Treatment Process in the Therapeutic Community: Associations with Retention and Outcomes Among Adolescent Residential Clients." Journal of Substance Abuse Treatment, 32(4), 415 - 421. https://doi.org/10.1016/j.jsat. $\underline{2006.10 .006}$ 
Empey, LaMar and Jerome Rabow. 1962. "Communist Rectification Programs and Delinquency Rehabilitation Programs: A Parallel?" American Sociological Review, 27(2), 256 - 258.

Frank, Jerome. 1974. Persuasion and Healing (Revised Edition). New York: Schocken Books.

Frankel, Barbara. 1989. Transforming Identities: Context, Power and Ideology in a Therapeutic Community. New York: Peter Lang.

Friedman, Robert M., Allison Pinto, Lenore Behar, Nicki Bush, Amberly Chirolla, Monica Epstein, Amy Green, Pamela Hawkins, Barbara Huff, Charles Huffine, Wanda Mohr, Tammy Seltzer, Christine Vaughn, Kathryn Whitehead, and Christina Kloker Young. Alliance for the Safe, Therapeutic and Appropriate use of Residential Treatment. 2006. "Unlicensed Residential Programs: The Next Challenge in Protecting Youth.” American Journal of Orthopsychiatry, 76(3), 295 - 303. https://doi.org/ $\underline{10.1037 / 0002-9432.76 .3 .295}$

Federal Trade Commission. 2019. "Residential Treatment Programs for Teens." https://www.consumer.ftc.gov/articles/0185-residential-treat$\underline{\text { ment-programs-teens }}$

Garcia, Angela. 2015. "Serenity: Violence, Inequality, and Recovery on the Edge of Mexico City." Medical Anthropology Quarterly, 29(4), 455 - 472. https://doi.org/10.1111/maq. 12208

Goffman, Erving. 1961. Asylums: Essays on the Social Situation of Mental Patients and Other Inmates. New York: Anchor Books.

Gowan, Teresa and Sarah Whetstone. 2012. "Making the Criminal Addict: Subjectivity and Social Control in a Strong-Arm Rehab." Punishment \& Society, 14(1), 69 - 93. https://doi.org/10.1177/1462474511424684

Harder, Annemiek T. and Erik J. Knorth. 2015. "Uncovering What is Inside the 'Black Box' of Effective Therapeutic Residential Youth Care." In Therapeutic Residential Care for Children and Youth: Developing Evidence Based International Practice, edited by James K. Whittaker, Jorge F. del Valle, and Lisa Holmes, 217 - 230. Philadelphia: Jessica Kingsley Publishers.

Harding, Jamie. 2013. Qualitative Data Analysis from Start to Finish. Los Angeles: SAGE. 
Harper, Nevin J. 2010. "Future Paradigm or False Idol: A Cautionary Tale of Evidence - Based Practice for Adventure Education and Therapy." Journal of Experiential Education, 33(1), 38 - 55.

https://doi.org/10.5193/JEE.33.1.38

Harrell, Sharon A. and Reginald C. Orem. 1980. Preventing Child Abuse and Neglect: A Guide for Staff in Residential Institutions. Washington, D.C.: U.S. Department of Health and Human Services, Office of Human Development Services.

Kaye, Kerwin. 2013. "Rehabilitating the 'Drugs Lifestyle': Criminal Justice, Social Control, and the Cultivation of Agency." Ethnography, 14(2), 207 - 232. https://doi.org/10.1177/1466138112457311

Knapp, Joseph L. and Frederick Weitzen, F. 1945. "A Total Psychotherapeutic Push Method as Practiced in the Fifth Service Command Rehabilitation Center, Fort Knox, Kentucky." The American Journal of Psychiatry, 102(3), 362-366. https://doi.org/10.1176/ajp.102.3.362

Leach, John. 2016. "Psychological factors in exceptional, extreme and torturous environments.” Extreme Physiology \& Medicine, 5(1), 7. https://doi.org/ $\underline{10.1186 / \mathrm{s} 13728-016-0048-\mathrm{y}}$

Lewin, Kurt. 1947. "Frontiers in Group Dynamics: Concept, Method and Reality in Social Science; Social Equilibria and Social Change." Human Relations, $1(1), 5-41$. https://doi.org/10.1177/001872674700100103

Lifton, Robert J. 1989. Thought Reform and the Psychology of Totalism: A Study of 'Brainwashing' in China. Chapel Hill: University of North Carolina Press.

Neville, Lucy, Sarah Miller, and Katarina Fritzon. 2007. "Understanding Change in a Therapeutic Community: An Action Systems Approach." Journal of Forensic Psychiatry \& Psychology, 18(2), 181 - 203. https://doi.org/ $\underline{10.1080 / 14789940601108439}$

Ofshe, Richard and Margaret T. Singer. 1986. "Attacks on Peripheral Versus Central Elements of Self and the Impact of Thought - Reforming Techniques." Cultic Studies Journal, 3(1), 3 - 24.

Polvere, Lauren. 2011. "Youth Perspectives on Restrictive Mental Health Placement: Unearthing a Counter Narrative.” Journal of Adolescent Research, 
Mark Chatfield - Totalistic Programs for Youth

26(3), 318-343.

https://doi.org/10.1177/0743558410391257

Rauktis, Mary Elizabeth. 2016. "When You First Get There, You Wear Red': Youth Perceptions of Point and Level Systems in Group Home Care." Child and Adolescent Social Work Journal, 33(1), 91-102. https://doi.org/ $\underline{10.1007 / \mathrm{s} 10560-015-0406-4}$

Reamer, Frederic G. and Deborah R. Siegel. 2008. Teens in Crisis: How the Industry Serving Struggling Teens Helps and Hurts Our Kids. New York: Columbia University Press. https://doi.org/10.7312/ream14462

Salter, Frank K. 1998. "Indoctrination and Institutionalized Persuasion: Its Limited Variability and Cross - Cultural Evolution.” In Ethnic Conflict and Indoctrination: Altruism and Identity in Evolutionary Perspective, edited by Irenäus Eibl - Eibsfeldt, and Frank K. Salter, 421 - 452. New York: Berghahn Books.

Schein, Edgar. 1962. "Man Against Man: Brainwashing.” Corrective Psychiatry and Journal of Social Therapy, 8(1-4), 90 - 97.

Schein, Edgar with Inge Schneier and Curtis Barker. 1961. Coercive Persuasion: A Socio-psychological Analysis of the 'Brainwashing' of American Civilian Prisoners by the Chinese Communists. New York: Norton.

Sickmund, Melissa, T. J. Sladky, W. Kang, and C. Puzzanchera. 2017. "Easy Access to the Census of Juveniles in Residential Placement." http://www.ojjdp.gov/ojstatbb/ezacjrp/

Singer, Margaret T. and Richard Ofshe. 1990. "Thought Reform Programs and the Production of Psychiatric Casualties.” Psychiatric Annals, 20(4), 188 193.

https://doi.org/10.3928/0048-5713-19900401-06

Stevens, Alisa. 2012. "'I Am the Person Now I was Always Meant to Be': Identity Reconstruction and Narrative Reframing in Therapeutic Community Prisons." Criminology \& Criminal Justice, 12(5), 527-547. https://doi.org/ $\underline{10.1177 / 1748895811432958}$

U.S. Census. 2018. "Characteristics of the Group Quarters Population in the United States 2017 American Community Survey 1 - Year Estimates." https://factfinder.census.gov/faces/tableservices/jsf/pages/productview.xhtml?pid=ACS 17 1YR S2601A\&prodType=table 
U.S. Department of Health \& Human Services, Administration for Children and Families, Administration on Children, Youth and Families, Children's Bureau. 2018a. "A National Look at the Use of Congregate Care in Child Welfare." https://www.acf.hhs.gov/sites/default/files/cb/cbcongregatecare_brief.pdf

U.S. Department of Health \& Human Services, Administration for Children and Families, Administration on Children, Youth and Families, Children's Bureau. (2018b). "Child Maltreatment 2016." https://www.acf.hhs.gov/cb/ research-data-technology/statistics-research/child-maltreatment

U.S. Government Accountability Office. 2008a. "GAO - 08 - 146T: Residential Treatment Programs: Concerns Regarding Abuse and Deaths in Certain Programs for Troubled Youth." United States Government Accountability Office Testimony Before the Committee on Labor and Education: House of Representatives. 2008. https://www.gao.gov/new.items/d08146t.pdf

U.S. Government Accountability Office. 2008b. "GAO - 08 - 346: Residential Facilities: Improved Data and Enhanced Oversight Would Help Safeguard the Well - Being of Youth with Behavioral and Emotional Challenges." https://www.gao.gov/new.items/d08346.pdf

U.S. Government Accountability Office. 2008c. "GAO - 08 - 713T: Residential Programs: Selected Cases of Death, Abuse, and Deceptive Marketing." https://www.gao.gov/assets/120/119828.pdf

U.S. House of Representatives, 110th Congress. 2007. "Cases of Child Neglect and Abuse at Private Residential Treatment Facilities: Hearing Before the Committee on Education and Labor." https://www.govinfo.gov/content/ pkg/CHRG-110hhrg38055/pdf/CHRG-110hhrg38055.pdf

U.S. House of Representatives, 110th Congress. 2008. "Child Abuse and Deceptive Marketing by Residential Programs for Teens: Serial No. 110 - 89." https://www.govinfo.gov/content/pkg/CHRG-110hhrg41839/html/ CHRG-110hhrg41839.htm

Walker, Sarah Cusworth, Brian K. Bumbarger, and Steven W. Phillippi. 2015. "Achieving Successful Evidence - Based Practice Implementation in Juvenile Justice: The Importance of Diagnostic and Evaluative Capacity." Evaluation and Program Planning, 52, 189 - 197. https://doi.org/ 10.1016/j.evalprogplan.2015.05.001

Whittaker, James K., Jorge F. del Valle, and Lisa Holmes. 2015. "Introduction: The current landscape of therapeutic residential care." In Therapeutic Residential Care for Children and Youth: Developing Evidence - Based International Practice, edited by James K. Whittaker, Jorge F. del Valle, 
Mark Chatfield - Totalistic Programs for Youth

and Lisa Holmes, 23 - 33. London \& Philadelphia: Jessica Kingsley Publishers.

https://doi.org/10.1080/0886571X.2016.1215755

Yin, Robert. 2016. Qualitative research from start to finish (Second Edition). New York: Guilford Press.

Zablocki, Benjamin. 1997. "The Blacklisting of a Concept: The Strange History of the Brainwashing Conjecture in the Sociology of Religion." Nova Religio: The Journal of Alternative and Emergent Religions, 1(1), 96 - 121.

https://doi.org/10.1525/nr.1997.1.1.96 